\title{
Erratum to: Crane scheduling for opportunistic remarshaling of containers in an automated stacking yard
}

\author{
Ri Choe - Tae Sung Kim • Taekwang Kim • \\ Kwang Ryel Ryu
}

Published online: 12 April 2014

(C) Springer Science+Business Media New York 2014

\section{Erratum to: Flex Serv Manuf J \\ DOI 10.1007/s10696-013-9186-3}

The authors would like to add the following acknowledgement to the original publication.

Acknowledgments This research was supported by MSIP (Ministry of Science, ICT \& Future Planning), Korea, under the ITRC (Information Technology Research Center) support program (NIPA2013-(H0301-13-1012)) supervised by the NIPA (National IT Industry Promotion Agency).

The online version of the original article can be found under doi:10.1007/s10696-013-9186-3.

R. Choe · T. S. Kim · T. Kim · K. R. Ryu $(\bowtie)$

Department of Electrical and Computer Engineering, Pusan National University, Busan,

Republic of Korea

e-mail: krryu@pusan.ac.kr 